\title{
PEMBELAJARAN PERSEN DENGAN MENGGUNAKAN MEDIA DOWNLOAD BAR PADA SISWA KELAS 5 SEKOLAH DASAR
}

\author{
Wuli Oktiningrum ${ }^{1}$ \\ ${ }^{1}$ Universitas Islam Raden Rahmat Malang
}

\begin{abstract}
This research was conducted on class $V$ students of SD Negeri 179 Palembang, with the aim of knowing students' understanding of the percent material by using media download bars. The subjects in this study were 28 students with heterogeneous abilities. The research methodology used in this study is Design Research with a Realistic Mathematics Education (RME) approach. This study fulfilled five characteristics of RME, namely the use of laptops, computers and downloads of the internet (using of context), pictures of download bars (use of models), activities in LKK (pupil own creations and contributions), presentation and group discussion (interactivity) and problems change fractions into percent (intertwining). The results of this study indicate that students have been able to solve the percent problem by using media download bars.
\end{abstract}

Keyword: Download Bar, Percent, RME, Design Research

\begin{abstract}
Abstrak: Penelitian ini dilakukan pada siswa kelas V SD Negeri 179 Palembang, dengan tujuan mengetahui pemahaman siswa pada materi persen dengan menggunakan media download bar. Subjek pada penelitian ini sebanyak 28 siswa dengan kemampuan yang heterogen. Metodologi penelitian yang digunakan pada penelitian ini adalah Design Research dengan pendekatan Realistic Mathematics Education (RME). Penelitian ini telah memenuhi lima karakteristik RME yaitu penggunaan laptop, computer dan download di internet (using of context), gambar bar download (penggunaan model), kegiatan pada LKK (pupil's own creations and contributions), presentasi dan diskusi kelompok (interactivity) dan masalah merubah pecahan kedalam bentuk persen (intertwining). Hasil penelitian ini menunjukkan bahwa siswa telah mampu menyelesaikan soal persen dengan menggunakan media download bar.
\end{abstract}

Kata Kunci: Download Bar, Persen, RME, Design Research

\footnotetext{
'Universitas Islam Raden Rahmat Malang, Email: wulie.okti国uniramalang.ac.id
} 


\section{PENDAHULUAN}

Kata "Persen" dan lambangnya "\%" merupakan hal yang sangat familiar bagi siswa, karena dua hal tersebut mudah ditemukan dalam kehidupan sehari - hari, seperti di pusat perbelanjaan atau di bank. Oleh karena itu, persen masuk dalam kurikulum sekolah untuk semua ilmu pengetahuan dan social (Baroody et all, 1998). Karena itu, dalam proses pembelajarannya alangkah lebih baiknya jika siswa dilibatkan atau diberikan kesempatan yang lebih dalam mengexplorasi kemampuannya memecahkan masalah persen (Van den Hauvel, 2003). Real mathematics Education (RME) merupakan suatu pendekatan pembelajaran yang tepat untuk mengajarkan persen kepada siswa, karena RME mengembangkan pemahaman matematika siswa terhadap konsep dan ide matematika dengan menggunakan eksplorasi terhadap masalah kontekstual yang berdasarkan pada proses penemuan (re-invention process) (Gravemeijer, 1994).

\section{Konsep Real mathematics}

Education (RME) juga sejalan dengan kebutuhan untuk memperbaiki pendidikan matematika di Indonesia yang didominasi oleh persoalan bagaimana meningkatkan pemahaman siswa tentang matematika dan mengembangkan daya nalar (Edy Tandiling, 2010). Menurut Zulkardi (2002) teori RME terdiri dari lima karakteristik yaitu (1)using of real context; (2) using model of mathematics; (3)pupil's own creation and contribution; (4) interactivity; dan (5) intertwining.

Tetapi pada kenyataannya, hasil belajar matematika siswa sekolah dasar terutama pada materi pecahan (termasuk persen dan desimal) masih tergolong rendah. Hal ini terbukti dengan hasil observasi dan wawancara dengan guru kelas 4 dan kelas 5 di SD Negeri 179 Palembang. Hasil observasi dikelas menunjukkan bahwa siswa masih bingung memecahkan masalah yang berkaitan dengan operasi pecahan, baik soal biasa maupun soal cerita. Hal ini terjadi karena siswa tidak hafal dengan perkalian sehingga untuk menyamakan penyebut membutuhkan waktu yang cukup lama.

Hal ini pun dipertegas oleh guru kelas 4 dan guru kelas 5, bahwa siswa kesulitan dalam memecahkan soal pecahan karena tidak hafal dengan perkalian, siswa malas membaca soal cerita, dan guru tidak memiliki media pembelajaran yang representative untuk menyampaikan materi pecahan. Berdasarkan hal tersebut, peneliti menawarkan suatu media pembelajaran yang sederhana dan sudah dikenal oleh siswa, media tersebut adalah Download Bar.

Download Bar merupakan indicator proses men-download atau mengunduh suatu file. Proses men-download bisa cepat atau lama tergantung dari koneksi internet. Berikut ini adalah contoh dari download bar yang digunakan sebagai media pembelajaran persen.

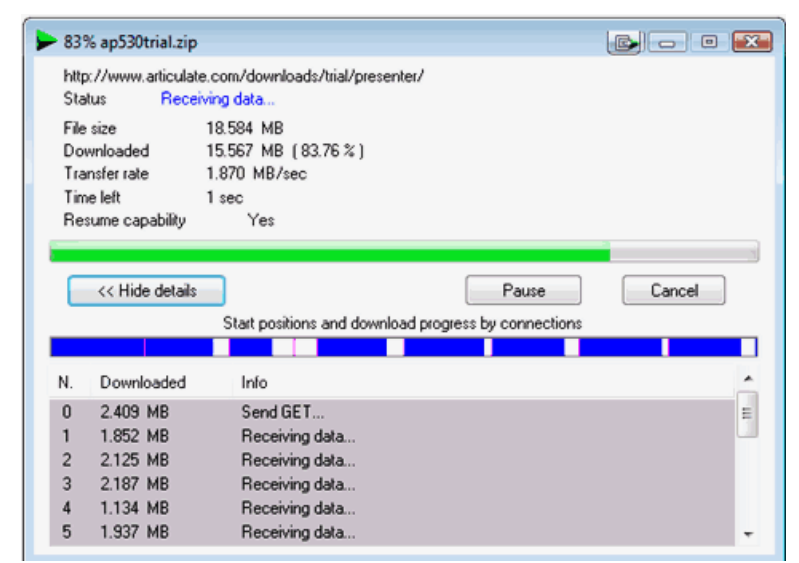

Gambar 1. Contoh Download Bar

Berdasarkan uraian di atas, maka tujuan dari penelitian ini dalah untuk mengetahui pemahaman siswa terhadap materi persen dengan menggunakan media download bar.

\section{METODOLOGI PENELITIAN}

Design research merupakan suatu metode yang digunakan dalam penelitian ini. Tujuan dari metode ini adalah untuk mengembangkan teori mengenai proses dan sarana pendukung dalam proses pembelajaran (Gravemeijer \& Cobb, 2006). 
Dalam Design Research menurut Gravemeijer \& Cobb (2006) terdapat tiga tahapan penting, yaitu :

1. Preparing for the experiment/ preparation and design phase (Bakker, 2004)

tujuan utama tahap ini adalah memformulasikan teori pembelajaran lokal (local instructional theory) yang dielaborasi dan diperbaiki selama pelaksanaan eksperimen. Hal-hal yang dilakukan dalam tahap ini adalah : (1) menganalisis tujuan yang ingin dicapai misalnya tujuan pembelajaran; (2) menentukan dan menetapkan kondisi awal penelitian; (3) mendiskusikan konjektur dari local instructional theory yang akan dikembangkan; (4) menentukan karakteristik kelas dan peran guru; serta (5) menetapkan tujuan teoritis yang akan dicapai melalui penelitian.

2. Design experiment

Tahap ini bukan untuk menguji apakah rancangan dan local instructional theory bekerja atau tidak, tetapi menguji dan mengembangkan local instructional theory yang telah dikembangkan serta memahami bagaimana teori itu bekerja selama eksperimen berlangsung.

3. Restrospective Analysis

Tujuan tahap ini adalah menganalisis data-data yang telah diperoleh untuk mengatahui apakah mendukung atau sesuai dengan konjektur yang telah dirancang. Data yang dianalisis meliputi rekaman video proses pembelajaran dan hasil interview terhadap siswa dan guru, lembar hasil pekerjaan siswa, catatan lapangan serta rekaman video dan audio yang memuat proses penelitian dari awal.

Penelitian ini dilaksanakan di kelas V SD Negeri 179 Palembang, dengan jumlah siswa sebanyak 28 orang. Data yang terkumpul dalam penelitian ini berupa video dan data tertulis. Video pada penelitian ini merekam semua kegiatan siswa dari awal pelaksanaan pembelajaran sampai akhir. Sedangkan data tertulis berisi tentang hasil kerja siswa serta catatan peneiti selama proses pembelajaran berlangsung.

\section{HASIL PENELITIAN DAN}

\section{PEMBAHASAN}

\section{Tahap 1 : Preliminary Design}

Dalam tahap ini dilakukan suatu kajian literatur mengenai topik yang akan digunakan. Standart kompetensi yang kami gunakan pada penelitian kali ini adalah menggunakan pecahan dalam pemecahan masalah. Dengan indikator pembelajaran yaitu megubah pecahan biasa ke bentuk persen. Tujuan pembelajarannya adalah siswa dapat merubah pecahan biasa kedalam bentuk persen. Selanjutnya, melakukan diskusi dengan guru mengenai penyesuaian jadwal mengajar, kondisi kelas berupa pengaturan siswa dalam kelompok dan keperluan pengajaran berupa alat dan bahan yang digunakan pada pembelajaran

a. Aktivitas I

Guru mengenalkan konteks download manager kepada siswa. Download manager merupakan salah satu software pengatur proses download dari internet ke dalam computer

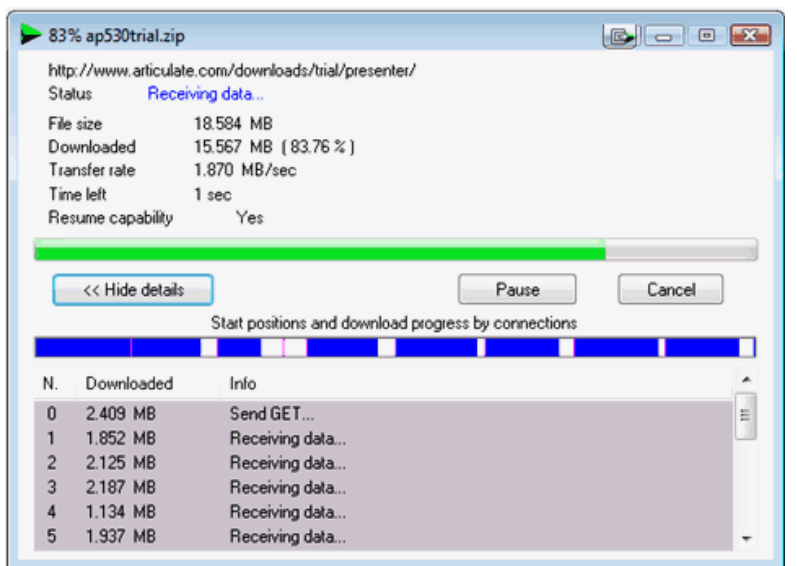

Gambar 2. Internet Download Manager

b. Aktivitas II

Siswa mendengar arahan dari guru tentang cara mengerjakan soal pada LKK. 
Siswa mengerjakan soal yang tersedia di LKK dengan cara menempel kertas hijau pada bar download yang telah tersedia di LKK berdasarkan persen download yang telah diketahui. Tujuan dari kegiatan ini adalah siswa bisa memahami posisi bilangan persen dalam suatu proses / kapasitas (25 persen, 20 persen, 50 persen, dan 75 persen dari 100 persen).

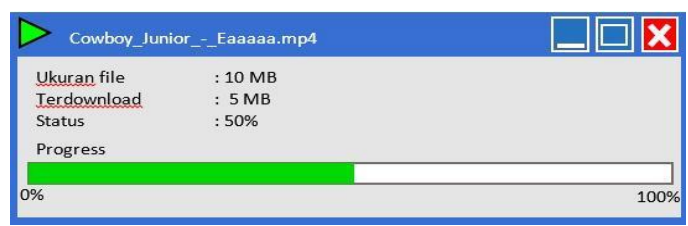

Gambar 3. Download manager yang sudah disederhanakan

c. Aktivitas III

Siswa mengerjakan soal pada lembar kedua LKK dengan mengarsir bar download yang telah dibagi menjadi 100 bagian (garis persen). Pada kegiatan ini siswa dituntut untuk memahami hubungan pecahan biasa yang disajikan dengan bentuk narasi dengan persen. Tujuan kegiatan ini adalah siswa diharapkan dapat mengarsir 25 persen, 20 persen, 80 persen, dan 30 persen dari 100 persen pada garis persen.

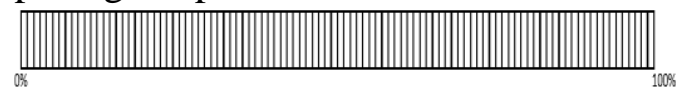

Gambar 4 . Garis persen

d. Aktivitas IV

Siswa diarahkan untuk menemukan pengertian persen, cara merubah pecahan biasa ke dalam persen dan mengaplikasikannya dalam memecahkan soal pada lembar ketiga LKK.

\section{Tahap 2 : Teaching Experiment}

Proses pembelajaran bermula dengan mengingatkan siswa tentang pecahan biasa dengan alat bantu kertas yang dibagi menjadi 2 bagian dan 4 bagian. Selanjutnya guru menjelaskan tujuan pembelajaran secara singkat dengan menggunakan konteks permasalahan sehari - hari yang terkait dengan materi yang akan dipelajari oleh siswa. Secara singkat pula guru menjelaskan kepada siswa tentang kegiatan yang akan dilakukan pada hari ini.

Selanjutnya guru bertanya kepada siswa tentang kebiasaan siswa dalam hal menyalakan laptop atau komputer. Secara aktif siswa menjawab bahwa sebelum halaman depan windows pada laptop atau komputer terbuka, mereka harus menungu beberapa saat sampai bar loading penuh atau $100 \%$. Dari kegiatan ini nampak bahwa siswa sering menjumpai bentuk persen dalam kehidupan sehari - hari.

Setelah kegiatan tersebut, guru membagi siswa kedalam 7 kelompok, setiap kelompok berisi 4 siswa. Hal ini bertujuan agar siswa bapat bekerjasama dengan baik. Setelah itu, guru membagi Lembar Kerja Kelompok (LKK) kepada masing - masing kelompok. Kemudian guru menjelaskan cara pengisian LKK. Pada kegiatan pertama siswa menempelkan kertas hijau kedalam bar download. Nampak beberapa kelompok tidak kesulitan dengan menentukan 25 persen, 50 persen da 75 persen, tetapi hampir keseluruhan kelompok kesulitan dalam menentukan 20 pesen bagian dari 100 persen. Hal ini terjadi karena dalam menentukan 25 persen, 50 persen, dan 75 persen, mereka hanya melipat kertas hijau menjadi 4 bagian dan 2 bagian, mereka nampak kesesusahan ketika harus membagi kertas hijau menjadi 5 bagian yang mewakili 20 persen.

Pada lembar kedua LKK, beberapa kelompok mengalami kesusahan dalam memahami soal, sehingga mereka membutuhkan bantuan dari guru. Pada lembar ketiga LKK, siswa menyelesaikan soal dengan cukup bagus. Mereka menjelaskan pengertian persen dan cara merubah pecahan biasa ke persen dengan menggunakan bahasa mereka sendiri.

Setelah selesai mengerjakan, siswa diminta oleh guru mempresentasikan hasil kerja. Guru memilih secara acak dari setiap perwakilan kelompok. Setiap kelompok 
diwakili oleh satu siswa dan dia berkewajiban umtuk memjelaskan hasil kerja kelompok. Karena terbatasnya waktu, yang dapat mempresentasikan hasil kerjanya hanya dua kelompok saja. Dan itu oleh guru sudah mewakili jawaban dari semua kelompok. Setelah itu guru bersama - sama dengan siswa menarik kesimpulan dari kegiatan pembelajaran yang telah mereka laksanakan. Guru bersama dengan siswa sepakat tentang pengertian persen dan cara merubah pecahan biasa kedalam persen. Setelah itu siswa diberi dua soal yang harus mereka pecahkan secara individu. Tujuan pemberian soal tersebut agar mengetahui tingkat pemahaman siswa tentang persen, dan agar mengetahui prosedur atau cara mereka dalam merubah pecahan biasa kedalam persen.

\section{Tahap 3 : Restropective Analysis}

Secara umum proses pelaksanaan pembelajaran berlangsung dengan baik dan lancar. Siswa terlihat antusias mengikuti setiap kegiatan baik kelompok maupun individu yang diberikan oleh guru. Setiap kelompok menunjukkan kerjasama yang baik dan kompak dalam mengerjakan setiap aktivitas yang diberikan. Setelah kegiatan pembelajaran usai, kami bersama guru mencoba menganalisis hasil kerja siswa. Perhatikan tabel berikut.

Tabel 1. Hasil Kegiatan

\begin{tabular}{|c|c|c|c|}
\hline \multirow[b]{2}{*}{ Kegiatan } & \multicolumn{2}{|c|}{ Hasil } & \multirow[b]{2}{*}{$\begin{array}{l}\text { Keterang } \\
\text { an }\end{array}$} \\
\hline & $\begin{array}{l}\text { Benar } \\
\text { Pengerja } \\
\text { an }\end{array}$ & $\begin{array}{l}\text { Salah } \\
\text { Pengerja } \\
\text { an }\end{array}$ & \\
\hline $\begin{array}{l}\text { LKK } \\
\text { Kegiatan } 1\end{array}$ & 7 & 0 & Kelompok \\
\hline $\begin{array}{l}\text { LKK } \\
\text { Kegiatan } 2\end{array}$ & 6 & 1 & Kelompok \\
\hline $\begin{array}{l}\text { LKK } \\
\text { Kegiatan } 3\end{array}$ & 5 & 2 & Kelompok \\
\hline $\begin{array}{l}\text { Evaluasi } \\
\text { Mandiri }\end{array}$ & 16 & 12 & Individu \\
\hline
\end{tabular}

Berdasarkan hasil table 1, pada kegiatan 1 LKK, semua kelompok menjawab dengan benar. Cara yang digunakan siswa untuk menemukan 25 persen dan 50 persen adalah dengan melipat kertas hijau menjadi 4 bagian dan 2 bagian. Kemudian menempelkan 1 bagian dari 4 bagian pada bar 25 persen dan 1 bagian dari 2 bagian pada bar 50 persen. Untuk soal no 3, mereka diminta menentukan 20 persen. Teknik yang digunakan hampir sama yaitu dengan cara melipat kertas hijau, tapi mereka kesulitan dalam membagi 5 sama besar, sehinga ada beberapa kelompok yang menggunakan penggaris dalam memecahkan masalah tersebut. Bahkan karena mereka tak kunjung segera menemukan hasil, mereka mengerjakan soal tersebut diakhir kegiatan 1.

Lain halnya dalam menentukan 75 persen, mereka mempunyai bervariasi cara untuk memecahkannya. Perhatikan gambar di bawah ini.

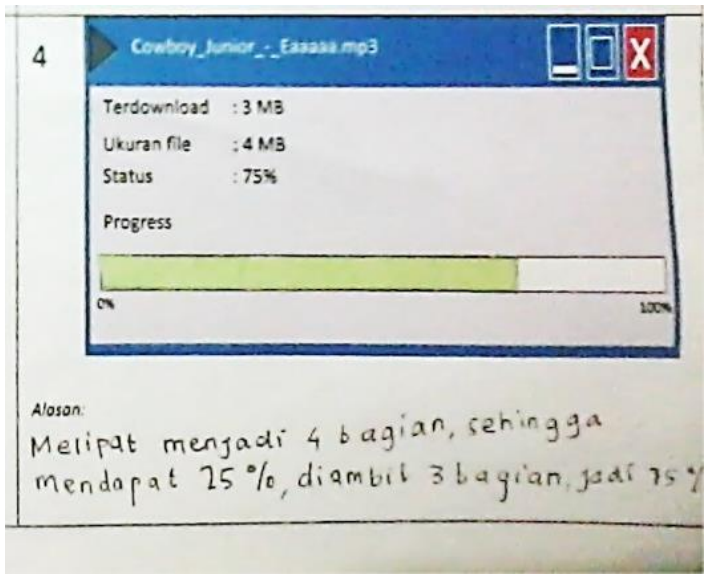

Gambar 5(a). Hasil kerja siswa

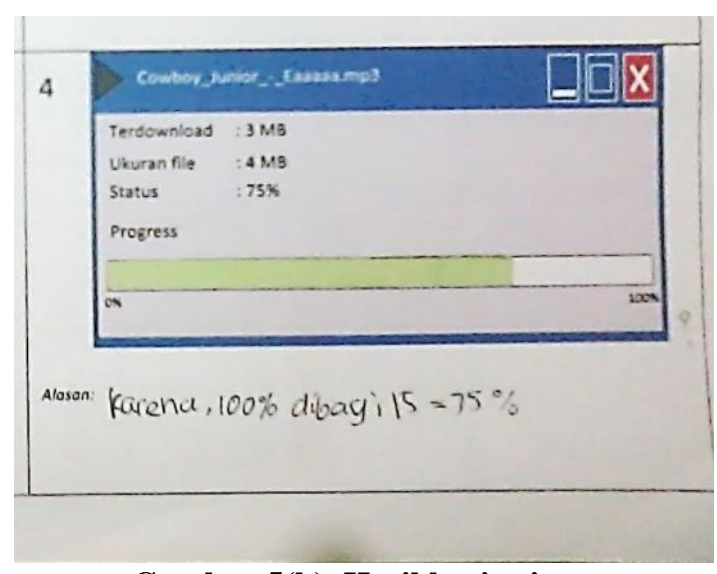

Gambar 5(b). Hasil kerja siswa 


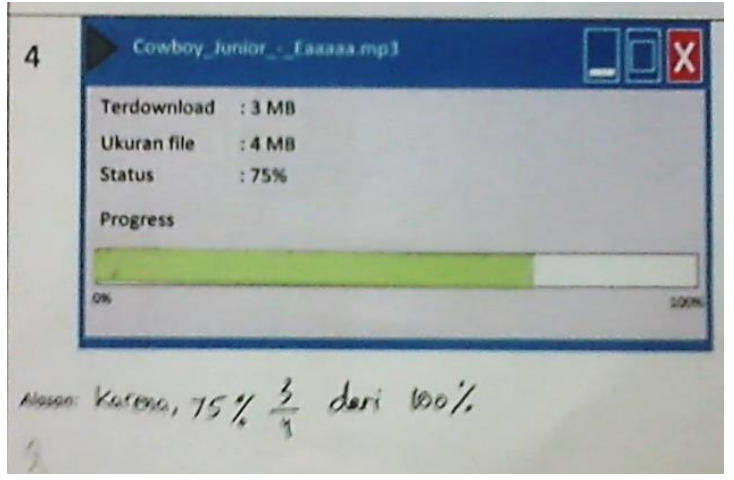

Gambar 5(c). Hasil kerja siswa

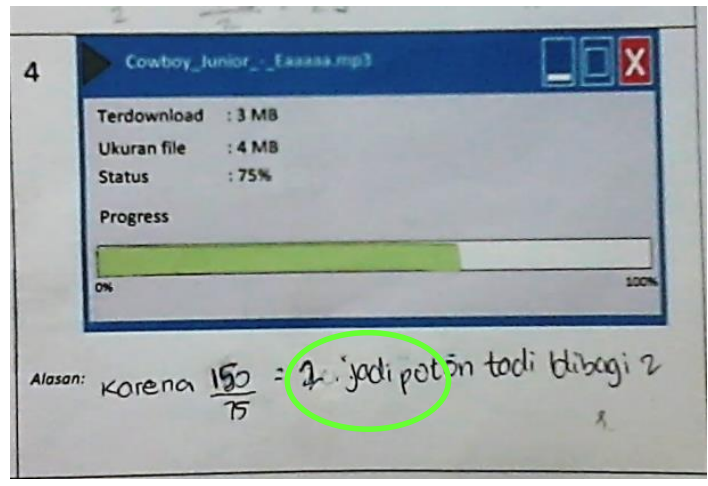

Gambar 5(d). Hasil kerja siswa

Untuk gambar 5(a). terlihat siswa menggunakan $25 \%$ sebanyak 3 bagian untuk membentuk $75 \%$. Sedangkan untuk gambar 5(b). terjadi kesalahan prosedur meski jawabannya benar. Gambar 5(c) memperlihatkan bahwa siswa mengetahui bentuk pecahan $75 \%$ adalah $\frac{3}{4}$. Kelompok yang mengerjakan seperti ditampilkan pada gambar 5(d). menggunakan teknik satu bar kertas (100\%) disambung dengan setengah bar kertas $(50 \%)$ kemudian gabungan itu mereka bagi menjadi 2 untuk memperoleh $75 \%$.

Pada kegiatan 2, banyak kelompok yang kesulitan dalam memahami soal, sehingga butuh bantuan guru untuk menjelaskannya. Cara siswa dalam memecahkan permasalahan pada lembar kedua LKK ini pun bervariasi. Hampr semua kelompok membagi garis persen menjadi 20 bagian, 25 bagian, dan 30 bagian. Dalam membagi garis persen, mereka menggunakan konsep pekalian dan pembagian. Tetapi karena kotak pada garis persen sangat kecil, kebanyakan siswa merasa kesulitan dalam menghitung. Perhatikan gambar berikut.

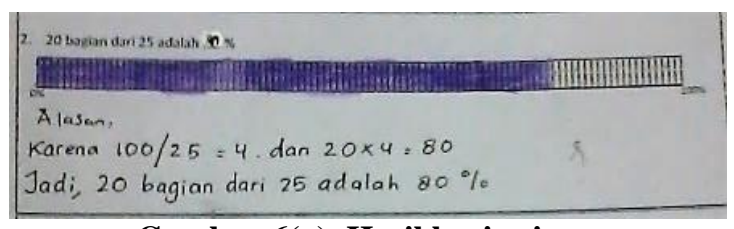

Gambar 6(a). Hasil kerja siswa

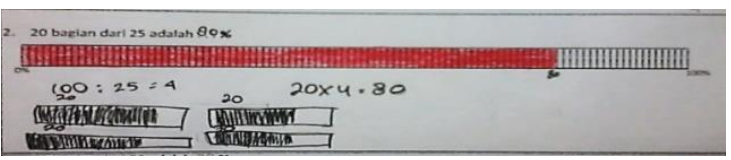

Gambar 6(b). Hasil kerja siswa

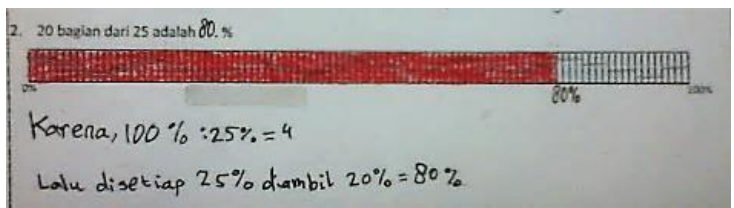

Gambar 6(c). Hasil kerja siswa

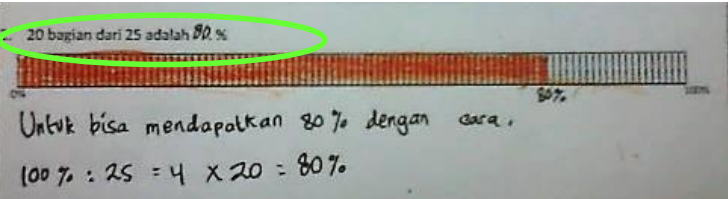

Gambar 6(d). Hasil kerja siswa

Pada gambar 6(a). Siswa nampak membagi garis persen menjadi 4 bagian, dimana setiap bagian terdiri dari 25 kotak kecil. Setelah itu mereka mengalikan bagian yang diarsir dan akhirnya mereka menemukan jawaban pada soal tersebut. Untuk gambar 6(b). Siswa menggunakan gambar yang lebih kecil untuk mempermudah kerja mereka. Pada gambar 6(c) siswa menjawab pertanyaan bahasa mereka sendiri, jawaban mereka benar tapi salah dalam penggunaan tanda persen. Dan untuk gambar 6(d). Siswa salah dalam menuliskan sistem operasi. Hampir semua kelompok melakukan hal yang sama, yaitu menuliskan operasi ganda.

Pada kegiatan ketiga siswa dituntut untuk membuat kesimpulan dari lembar 1 dan 2, mereka dituntut untuk menjelaskan definisi persen, cara mengubah pecahan biasa menjadi persen, dan mengaplikasikannya dalam memecahkan soal. Dan, hasilnya hampir seluruh kelompok menjawab bahwa definisi persen adalah perseratus, dan cara mengubah 
pecahan ke dalam bentuk persen adalah dengan membagi dan mengali.

Setelah kegiatan diskusi berakhir, guru membagikan satu lebar kertas yang berisikan dua soal. Tujuan pemberian soal tersebut yaitu mengukur kemampuan siswa dalam memahami materi yang telah mereka pelajari. Tetapi ternyata dari 28 siswa, ternyata 16 siswa mampu menjawab dengan benar dan 12 siswa salah dalam mengerjakan. Berdasarkan hasil kerja siswa tersebut, kami menyimpulkan bahwa sebagian siswa memahami konsep dasar pecahan dan mengetahui cara merubah pecahan biasa ke dalam persen. Tetapi karena mereka perlu pengembangan materi yang lebih lanjut untuk meningkatkan kemampuan mereka.

\section{KESIMPULAN}

Pada kegiatan penilitian ini, guru mengajarkan indikator mengubah pecahan biasa ke dalam bentuk persen dengan menggunakan download bar sebagai media. Teknik pembelajaran dengan menggunaan pendekatan RME dan telah memenuhi lima karakterisitik RME yaitu, penggunaan laptop, computer dan download di internet (using of context), gambar bar download (penggunaan model), kegiatan pada LKK (pupil's own creations and contributions), presentasi dan diskusi kelompok (interactivity) dan masalah merubah pecahan kedalam bentuk persen (intertwining). Proses matematisasi yang terjadi dapat digambarkan pada iceberg di bawah ini.

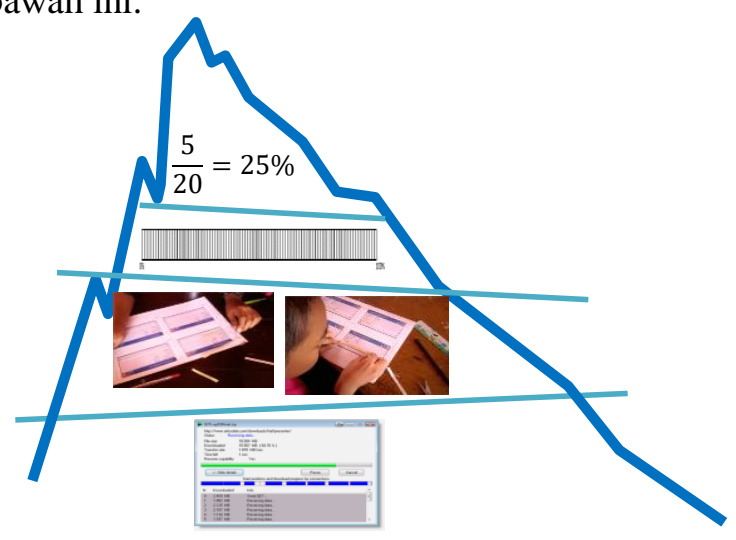

Gambar 12. Iceberg pembelajaran

Konteks yang digunakan adalah sesuatu yang dekat dengan siswa, yaitu cara menyalakan laptop atau komputer, dan download file diinternet. Dengan menggunakan konteks tersebut siswa dapat menentukan 20 persen, 25 persen, 50 persen, 75 persen dari 100 persen dengan mudah, dan diharapkan dapat meningkatkan hasil belajar siswa.

\section{DAFTAR PUSTAKA}

Bakker, Arthur (2004). Design research in statistics education: On symbolizing and computer tools. Desertasi Doktor pada Utrech University : Tidak diterbitkan.

Baroody, A. J., \& Ronald, T. C. (1998). Fostering children's mathematical power. London: Lawrence Elbaum Associates Publisher.

Gravemeijer, K P. E. (1994). Developing Realistic Mathematics Education. Nedherlad. Freudential Institute

Gravemeijer, K., \& Cobb, P. (2006). Design research from a learning design perspective, in Van den Akker, J., Gravemeijer, K., McKenny, S., and Nieveen, $\mathrm{N}$ (Editor) Educational Design research, hal. 17-51. London: Routhledge.

Tandiling, Edy. (2010). Implementasi Realistic Mathemarics Education (RME) Di Sekolah. Jurnal Guru Membangun Vol .25 No. 3.

Van den Hauvel \& Panhuizen, M. (2003). The didactical use of models in realistic mathematic education: An example from a longitudinal trajectory on percentage. Educational studies in mathenatics, vol. 54(1). 9-35.

Zulkardi. (2002). Developing a learning environment on realistic mathematics education for Indonesian Student Teachers. Doctoral Dissertation. Enschede: University of Twente 